where necessary, throughout the antenatal period, especially in low socioeconomic groups?

JoHN H SMITH

Rotunda Hospital,

Dublin, Eire

${ }^{1}$ Lechtig A, Habicht JP, Delgado H, Klein RE, Yarbrough C, Martorell R. Pediatrics $1975 ; 56$ :

2 Primrose 257-64.

\section{Monitoring blood glucose}

SIR,-Mary Warner (15 December, p 1581) and Dr R D Eastham (12 January, p 116) have both quite rightly cautioned us on the indiscriminate and unsupervised use of blood glucose meters and one has to agree with many of the points made. The biochemistry laboratory should indeed be able to produce the more accurate results, and results from meters in some clinical situations, operated by a variety of personnel, may at times be suspect. However, even with all the limitations of interpretation of the single clinic blood glucose estimation, it is far more valuable if the result is available at the time of the consultation; and this in many hospitals and outlying clinics can be provided only by a meter and strip system. The responsibility for such a system must lie with the clinician, who should be constantly checking quality control with the assistance of his biochemical colleagues.

With regard to self-monitoring by the patient, one fundamental question is in danger of being overlooked-who needs to know the blood glucose results? The answer is that it is the patient who needs the result and he or she needs it at the time of the test, not two or three days later. The patient must be trained to react to abnormal patterns of results by making sensible changes of treatment. If this is not done then the full potential of self-monitoring is not being realised. Thus filter paper strips sent to the laboratory, as described by Dr R Paisey and others (8 December, $p$ 1509), provide only a partial self-monitoring system. A coefficient of variation of less than $10 \%$ is adequate for day-to-day diabetic management and may be achieved by suitably trained patients using meters and strip tests at home. ${ }^{1}$ Quality control is important with self-monitoring even if more difficult to organise than in the hospital. The clinician must be satisfied that the patient is well trained, maintains good technique, and responds appropriately to the results. The blood glucose meters and strip systems must be kept under critical review and must be shown to live up to the manufacturers' specifications when put into the hands of the trained patient.

Self-monitoring of blood glucose may be a real advance for many patients. Producing inaccurate results will give it a bad name but so will limiting its potential by giving the result to the doctor in preference to the patient.

\section{A H KNIGHT $\begin{aligned} & \text { St Thomas's Hospital, } \\ & \text { London SE1 7EH }\end{aligned}$}

Stoke Mandeville Hospital,
Aylesbury, Bucks HP21 8AL

${ }^{1}$ Webb DJ, Lovesay JM, Ellis A, Knight AH. Br Med $\mathcal{f}$ In press.

SIR,-We read with interest the paper by Dr I Peacock and others on self-monitoring of blood glucose during diabetic pregnancy (24 November, p 1333).
Our own experience using the Ames Dextrostix-Eyetone reflectance meter system is very similar in a series of 24 unselected consecutive patients (21 established diabetics - duration of insulin therapy nine years, range 0.5 to 26 years - and three gestational diabetics on insulin). However, our patients made three to four measurements of preprandial blood glucose daily and were taught and encouraged to modify their own insulin doses to achieve optimal diabetic control. We have found that in many patients there are abrupt changes in insulin dose requirements, particularly towards the end of the second trimester. Weekly profiles, no matter how detailed, do not yield enough information in such patients. Furthermore, postprandial measurements of blood glucose do not appear to be particularly helpful in that high concentrations after breakfast seem to be predictable from the value before breakfast. We are, however, in agreement with the authors' comments about the dangers of nocturnal hypoglycaemia, although we have not found it necessary to advise a third injection for this reason.

Collection of blood samples at home for processing in the laboratory (Dr R B Paisey and others, 8 December, p 1509) may be a useful method of checking on the correctness of patients' measurements but does not have the same educational value as true selfmonitoring of blood glucose. In addition, surveillance can be improved by unheralded visits from a health visitor or specialist nurse.

Measurement of glycosylated haemoglobin concentrations in the pregnant diabetic is too insensitive a method to detect any but the more gross forms of aberration in diabetic control. In our hands normal haemoglobin $A_{1}$ concentrations (measured by the microcolumn method) can be achieved even when blood glucose is normal. Hb $\mathrm{A}_{1}$ estimations give no clue about the swings of blood glucose (either hyperglycaemia or hypoglycaemia).

By involving the patients in their own diabetic control motivation and understanding of the aims of diabetic treatment are greatly enhanced. Although shortening of the period of hospitalisation was not our prime aim, we found this easy to achieve save in women with established diabetes of 10 years or more. In this group the maternal course during pregnancy was frequently complicated despite good control of blood glucose, although the fetal outcome was as good as in the group with duration of maternal diabetes of less than 10 years. This method of blood glucose surveillance and diabetic control was acceptable to all our patients and no problems arose as a result of the frequent capillary blood sampling.

\section{T E T WEST}

Royal Shrewsbury Hospital,
Shrewsbury, Shropshire

E E EDWARDS

Clara Lowy

S L JUDD

SIR,-As Dr R D Eastham states (12 January, $p$ 116), the days of the single clinic blood glucose estimation for assessment of treatment of diabetes mellitus are numbered. Glycosylated haemoglobin may become a better measure of general diabetic control at intermittent clinic visits. However, frequent blood glucose estimations are required to provide the up-to-date information necessary for rational adjustment of insulin dosage.

Home monitoring of blood glucose levels is a practical procedure ${ }^{1}$ and, given the current mode of insulin administration, exact glucose levels as provided by a clinical chemistry laboratory are unnecessary for this purpose. Blood glucose levels may be estimated with glucose oxidase-peroxidase test strips using a colour comparison scale without the need to purchase a reflectance meter. ${ }^{2}$ We have not found these newer test strips liable to variation. Clearly the laboratory estimation of plasma glucose remains essential for glucose tolerance tests and for management of patients during intercurrent illness and in diabetic emergencies (and for the calibration of blood glucose meters). But diabetic patients who have achieved better diabetic control through home monitoring ${ }^{3}$ should not abandon the method because it has not yet reached the precision expected of laboratories.

C M KESSON

PaUL LAWSON JOHN T IRELAND

Department of Medicine, Southern General Hospital, Glasgow G51 4TF 1 Sönksen PH, Judd SL, Lowy C. Lancet 1978;i :729-32.
2 Lawson PM, Kesson CM, Ireland JT. Lancet 1979; ${ }^{2}$ Lawson

${ }_{3}$ Tattersall RB. Diabetologia 1979;16:71-4.

\section{Postoperative analgesia}

SIR,-Dr P C Rutter and others (5 January, p 12) have clearly shown that continuous intravenous opiate analgesia following abdominal surgery produces better analgesia for less opiate. Vital capacity and peak expiratory flow rate are improved and pulmonary complications are fewer with this regimen than with the two more commonly employed alternatives.

It would be interesting to know the arterial blood oxygen and carbon dioxide tensions and $\mathrm{pH}$ in the three patient groups during treatment, for these findings would have implications for the postoperative management of patients who have preoperative impairment of pulmonary function. Analgesia is often given reluctantly to such patients on the grounds that it may cause or exacerbate respiratory failure. If the patients in groups $B$ and $C$ were more hypoxic and hypercapnic than those in group $\mathrm{A}$ this might suggest that adequate analgesia by infusion of opiates is more likely to secure optimal pulmonary function even in patients at risk of respiratory failure because of lung disease. Postoperative pain resulting from a reluctance to prescribe opiates for these patients may be more likely to cause respiratory failure than adequate opiate analgesia.

A G LeItch

Department of Respiratory Medicine, Edinburgh EH10 5SB

** We sent a copy of this letter to the authors, and Professor H A F Dudley's reply on behalf of his colleagues is printed below.-ED, $B M \mathcal{F}$.

SIR,-Dr Leitch is quite right in saying that the reluctance to give opiates to patients with borderline respiratory function when they suffer the additional embarrassment of pain may not be soundly based. However, we cannot 